\title{
Fatigue Strength Improvement by Replacing Welded Joints with Ductile Cast Iron Joints
}

\author{
Tetsuro HIDAKA, ${ }^{1) *}$ Nao-Aki NODA, ${ }^{2)}$ Yoshikazu SANO, ${ }^{2)}$ Nobuhiro KAI ${ }^{1)}$ and Hiroyoshi FUJIMOTO ${ }^{1)}$ \\ 1) Research and Development Center, HINODE, Ltd., Iwasaki, Harakoga, Miyaki-cho, Miyaki-gun, Saga, 849-0101 Japan. \\ 2) Dept. of Mechanical and Control Engineering, Kyusyu Institute of Technology, 1-1 Sensui-cho, Tobata-ku, Kitakyusyu, \\ Fukuoka, 804-8550 Japan.
}

(Received on April 12, 2019; accepted on May 7, 2019; originally published in Tetsu-to-Hagané, Vol. 105, 2019, No. 6, pp. 619-628; J-STAGE Advance published date: July 30, 2019)

\begin{abstract}
In this study fatigue experiments are conducted for ductile cast iron (DCl) to compare with the fatigue strength of cruciform welded joints. Here, several DCl specimens are prepared to have nearly the same fatigue strength in smooth specimens before welding and to have similar cruciform shapes in the welded joints. It is found that the fatigue strength of $\mathrm{DCl}$ specimen is about three times larger than that of the welded joint specimens. The fatigue strength improvement can be explained in terms of the small stress concentration factor, notch insensitivity and compressive residual stress generated by shot blasting for $\mathrm{DCl}$ joints.
\end{abstract}

KEY WORDS: fatigue strength; ductile cast iron; welded joint; stress concentration; notch insensitivity; residual stress.

\section{Introduction}

Welded structures include a lot of geometrical discontinuities and material dissimilarities caused by welding with rapid heating/quenching processes. Such stress concentration portions sometimes cause fatigue crack initiation, propagation and final fracture accelerated by the residual stress and welding defects. Countermeasures have been requested especially from civil engineering fields to design bridges, road facilities and so on. ${ }^{1,2)}$

In contrast, ductile cast iron $\mathrm{DCI}^{3,4)}$ has excellent formability to mold complex geometries by casting. DCI enables us to avoid sudden cross-sectional change and design desirable geometries to reduce stress concentration. Also DCI has high strength and toughness comparable to steel materials. $^{5-7)}$ Furthermore, in the sand mold casting, DCI may reduce the residual stress by cooling gradually. Therefore, the DCI fatigue strength can be improved higher than the fatigue strength of welded structures. In recent years, attention has been paid to the fatigue strength superiority of DCI. Several DCI products are also being developed by replacing welded structures. ${ }^{8,9)}$

However, ductile cast iron has not been commonly used as a structural member. This is because DCI has lower fatigue strength, ${ }^{10,11)}$ lower Charpy impact value, ${ }^{12-15)}$ and more casting defects compared to steel. No experimental data is available directly comparing the fatigue strengths of the welded joint and the ductile cast iron. Because of those reasons, ductile cast iron is not currently used as a fatigue

\footnotetext{
* Corresponding author: E-mail: t-hidaka@hinodesuido.co.jp DOI: https://doi.org/10.2355/isijinternational.ISIJINT-2019-237
}

durable member.

Based on the above background, in this research, the fatigue strength will be verified experimentally when replacing the welded joint with DCI. Then, the fatigue strengths will be compared experimentally and theoretically by considering several effects.

\section{Fatigue Strength Characteristics of Non-load- carrying Cruciform Welded Joints}

The fatigue strength of the welded joint varies mainly depending on type of joint and the toe treatment. For example, types of joints include butt joints and cruciform joints. The toe treatment includes as welded, grinding, and the like. From the above, the fatigue strength of the welded joint is prescribed by classified into several design standard strength class depending on the joint type and the toe treatment type, each of which experimentally obtained for each type of joint and the toe treatment. ${ }^{16)}$ In this paper, as shown in Fig. 1, the cruciform welded joints ${ }^{16)}$ will be considered for non-load-carrying type, whose strength is higher than load-carrying type. Hereinafter referred to as the welded joint. Since this welded joint has a complicated shape and many welding points, there is a great advantages by replacing with DCI members. It should be noted that the DCI member considered in this study is close to the shape frequently used for reinforcing ribs and so on. Furthermore, this welded joint has relatively larger fatigue strength among similar cruciform joints and many experimental data are available.

Figure 2 shows the fatigue experimental results ${ }^{17)}$ for the welded joint of JIS SM 50 B in comparison with the smooth 
specimen of the SM 50 B. Hereinafter referred to as steel plate before welded or simply before welded. This data is quoted from the fatigue data sheet of National Research Institute for metals, ${ }^{17}$ ) which has been often used as the design standard of welded joints in Japan. Figure 1 shows the shape of the welded joint used in the experiment, and Fig. 2 shows the shape of the steel plate before welded. In Fig. 1, the weld toe radius $\rho$ of the welded joint is $\rho=0.485$ $\mathrm{mm}$, which is the average value of 29 specimens. It is unknown whether the grinding treatment has been done at the toe or not. Figure 3 shows the microstructure of the welded joint, Table 1 shows the chemical composition of the steel plate before welded, Table 2 summarizes the mechanical properties of the steel plate before welded and the fatigue test results in Fig. 2. As shown in Table 2, the fatigue strength of the welded joint $\sigma_{w 1}^{\text {STEEL }}=80 \mathrm{MPa}$, which

Stress concentration factor $K_{t}=3.47$
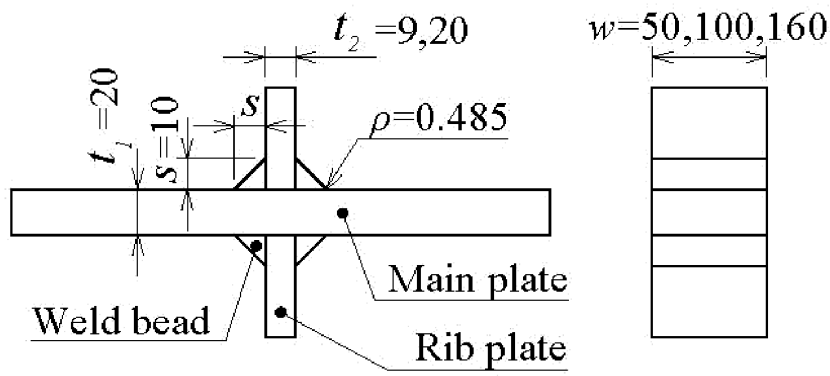

Fig. 1. Dimension of welded joint $\left(t_{1}=20\right)$.

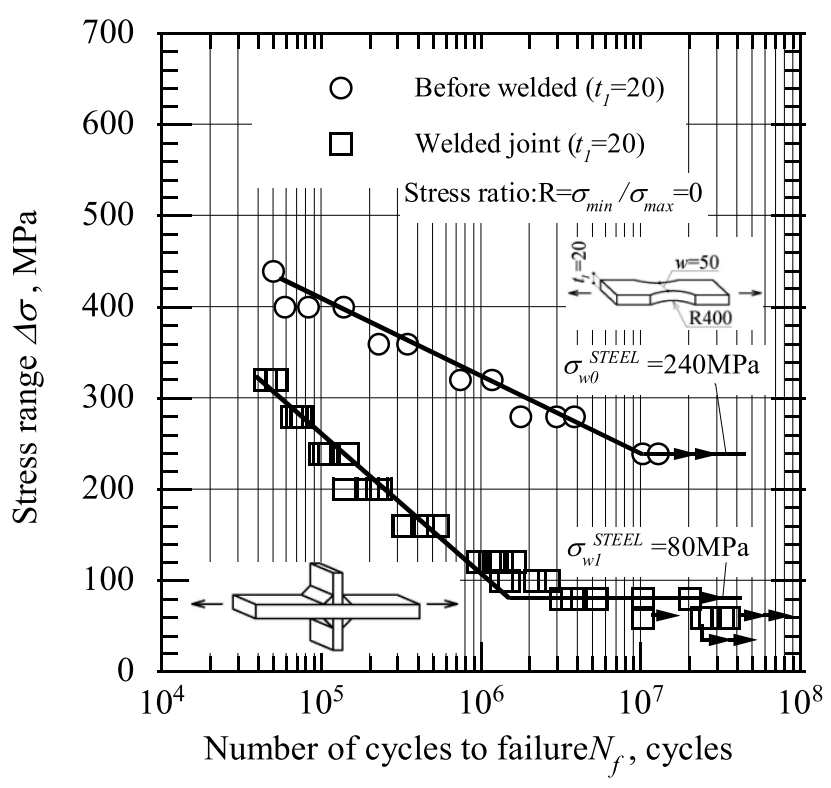

Fig. 2. $S-N$ diagram showing fatigue properties of before welded and welded joint $\left(t_{1}=20\right)$. is remarkably small, that is, only $30 \%$ of the fatigue strength $\sigma_{w 0}^{\text {STEEL }}=240 \mathrm{MPa}$ of the steel plate before welded. Thus, it is found that the welded joint cannot show the original strength of the steel material. It is known that the fatigue strength decreases with increasing the main plate thickness $t_{1}$. It is also known that the effect of plate width $w$ and rib thickness $t_{2}$ on the fatigue strength is small. ${ }^{18)}$

The reason why the fatigue strength decreases is known as the stress concentration at the weld toe included welding structures and the residual stress generated at the welded part. ${ }^{19-21)}$ The stress concentration factor $K_{t}$ can be estimated as $K_{t}=3.47$ from the analysis described later. Although several methods are available to reduce $K_{t}$ at the weld toe, in reality, as-welded state often can be seen due to the balance of costs and so on. In Table 2, the residual stresses measured at the welded joints are not summarized. However, as an example, the tensile residual stress about 300 to $400 \mathrm{MPa}$ was reported in the vicinity of the weld toe. This is close to the yield strength of the base metal whose tensile strength is about $500 \mathrm{MPa}$. It was told that this residual stress may reduce the fatigue strength. ${ }^{22)}$

\section{Fatigue Experiment for DCI Joints}

In this section, the fatigue experiment for DCI joint will be explained with the dimensions of the test specimen to replace the welded joint with the ductile cast iron.

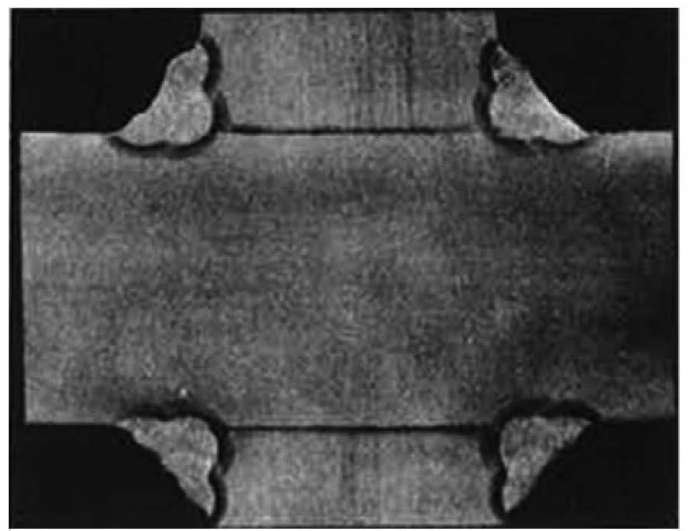

$10 \mathrm{~mm}$

Fig. 3. Macrostructure of welded portion (Etched by nital).

Table 1. Chemical composition of steel plate before welded (wt\%).

\begin{tabular}{cccccc}
\hline $\mathrm{C}$ & $\mathrm{Si}$ & $\mathrm{Mn}$ & $\mathrm{P}$ & $\mathrm{S}$ & $\mathrm{C}_{\mathrm{eq}}{ }^{*}$ \\
\hline 0.166 & 0.33 & 1.45 & 0.021 & 0.011 & 0.42 \\
\hline
\end{tabular}

*Carbon equivalent $\mathrm{C}_{\mathrm{eq}}=\mathrm{C}+\mathrm{Mn} / 6+\mathrm{Si} / 24+\mathrm{Ni} / 40+\mathrm{Cr} / 5+\mathrm{Mo} / 4+\mathrm{V} / 14$

Table 2. Mechanical and fatigue properties of steel plate before welded and welded joint.

\begin{tabular}{|c|c|c|c|c|c|c|}
\hline \multicolumn{3}{|c|}{ JIS Z 2201(1968) No. 1A type tensile test specimen } & \multicolumn{2}{|c|}{ Steel plate before welded } & \multicolumn{2}{|c|}{ Welded joint } \\
\hline $\begin{array}{c}\text { Upper yield stress } \\
(\mathrm{MPa})\end{array}$ & $\begin{array}{l}\text { Tensile strength } \\
\qquad(\mathrm{MPa})\end{array}$ & $\begin{array}{c}\text { Elongation } \\
(\%)\end{array}$ & $\begin{array}{c}\text { Vickers hardness } \\
(H V 98 \mathrm{~N})\end{array}$ & $\begin{array}{c}\text { Fatigue limit } \Delta \sigma \\
(\mathrm{MPa})\end{array}$ & $\begin{array}{c}\text { Vickers hardness* } \\
(H V 98 \mathrm{~N})\end{array}$ & $\begin{array}{c}\text { Fatigue limit } \Delta \sigma \\
(\mathrm{MPa})\end{array}$ \\
\hline 397 & 534 & 31 & 154 & 240 & $225-250$ & 80 \\
\hline
\end{tabular}

*Maximum hardness of heat affected zone 


\subsection{Joint Fatigue Test Specimen}

Figure 4 shows the specimen dimensions. To clarify DCI joint strength is larger than welded joint strength, we use the main plate thickness of DCI $t_{1}=24 \mathrm{~mm}$, which is larger than the one of welded joint $t_{1}=20 \mathrm{~mm}$. Since the plate width, the rib thickness, and the rib height have little influence on the fatigue strength, they are set to the dimensions as shown in Fig. 4 by considering the load capacity of the testing machine and for convenience in manufacturing. The intersection of the main plate and ribs is smoothly connected with $\rho=6 \mathrm{~mm}$ (see Fig. 4). This value is smaller than the leg length $\mathrm{s}=10 \mathrm{~mm}$ of the welded joint shown in Fig. 1, which is empirically set by consideration of casting defects. The gripping portion is thickened by $9 \mathrm{~mm}$ against the main plate thickness for reinforcement. Draft angle required for casting production is set to 1 degree in the main plate thickness direction. The change in plate width of the main plate due to this draft angle is $0.5 \mathrm{~mm}$ or less. For the fatigue experiment of smooth specimens, for the sake of convenience, the test specimen having a cross shape similar to that of a DCI joint and having a main plate thickness $t_{1}=12 \mathrm{~mm}$ is used (See Fig. 4). Hereinafter, this test specimen will be referred to as DCI plate. Since all of the fracture positions of this specimen were situated at the smooth portions, it was substituted as the smooth specimen.

Note that iron castings are not usually machined but are often used in as-cast surface condition called casting surface. Usually surface defects such as irregularities and sand inclusions are included on the casting surface, and it is known that the fatigue strength decreases compared to the machined surface. ${ }^{23,24)}$ Therefore, in this study, in order to obtain the results close to the practical fatigue strength, the fatigue test is carried out with both DCI joint and DCI plate as casting surface. In addition, steel shot blast for sand removal is done because this is also commonly used.

Table 3 shows the chemical composition of DCI joint. Since the fatigue strength is generally correlated with the tensile strength of the specimen, the tensile strength of DCI joint should be equal to that of the welded joint to be compared. Therefore, referring to Table 2, the chemical composition of DCI joint was adjusted so that the tensile strength was equivalent to $550 \mathrm{MPa}$. Table 4 shows the mechanical properties of DCI joint. These mechanical properties were obtained by cutting out JIS No. 14 B type tensile test specimen from DCI joint by machine processing and carrying out a tensile test as shown in Fig. 5. From these results, it is confirmed that the tensile strength of the cast iron joint

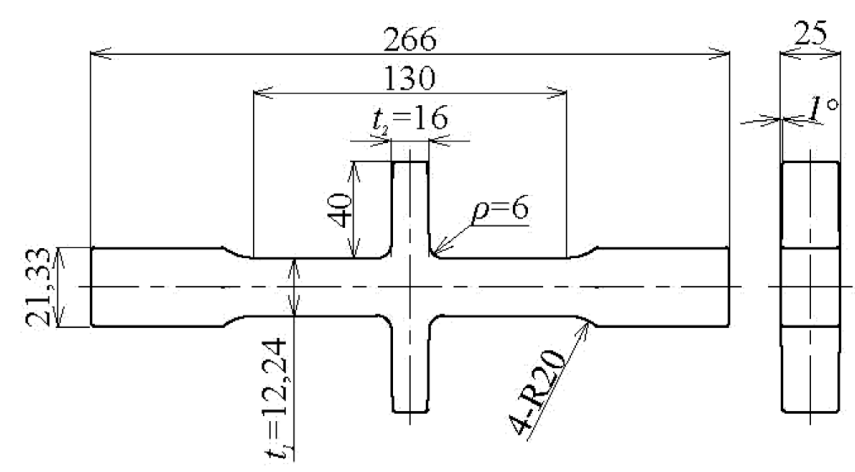

Fig. 4. Dimension of DCI joint. is almost the same as the welded joint shown in Table 2. Figure 6 shows the microstructure of DCI joint. From this, this test specimen was a bull's eye structure found in general ductile cast iron. The chemical composition and mechanical properties of DCI plate $\left(t_{1}=12 \mathrm{~mm}\right)$ were almost the same as those of DCI joint.

\subsection{Fatigue Test Condition}

The fatigue load was set as the axial tensile load in the

Table 3. Chemical composition of DCI joint (wt\%).

\begin{tabular}{cccccccc}
\hline $\mathrm{C}$ & $\mathrm{Si}$ & $\mathrm{Mn}$ & $\mathrm{P}$ & $\mathrm{S}$ & $\mathrm{Cu}$ & $\mathrm{Mg}$ & $\mathrm{C}_{\mathrm{eq}}{ }^{*}$ \\
\hline 3.67 & 2.45 & 0.41 & 0.024 & 0.004 & 0.31 & 0.042 & 3.84 \\
\hline *Carbon equivalent & $\mathrm{C}_{\mathrm{eq}}=\mathrm{C}+\mathrm{Mn} / 6+\mathrm{Si} / 24+\mathrm{Ni} / 40+\mathrm{Cr} / 5+\mathrm{Mo} / 4+\mathrm{V} / 14$
\end{tabular}

Table 4. Mechanical properties of DCI joint.

\begin{tabular}{cccc}
\hline \multicolumn{4}{c}{ JIS Z 2241(2017) No. 14 B type tensile test specimen } \\
\hline $\begin{array}{c}\text { 0.2\% Proof stress } \\
(\mathrm{MPa})\end{array}$ & $\begin{array}{c}\text { Tensile strength } \\
(\mathrm{MPa})\end{array}$ & $\begin{array}{c}\text { Elongation } \\
(\%)\end{array}$ & $\begin{array}{c}\text { Brinell hardness } \\
(\mathrm{HB})\end{array}$ \\
\hline 340 & 560 & 15.8 & 191 \\
\hline
\end{tabular}

JIS Z 2241(2017)

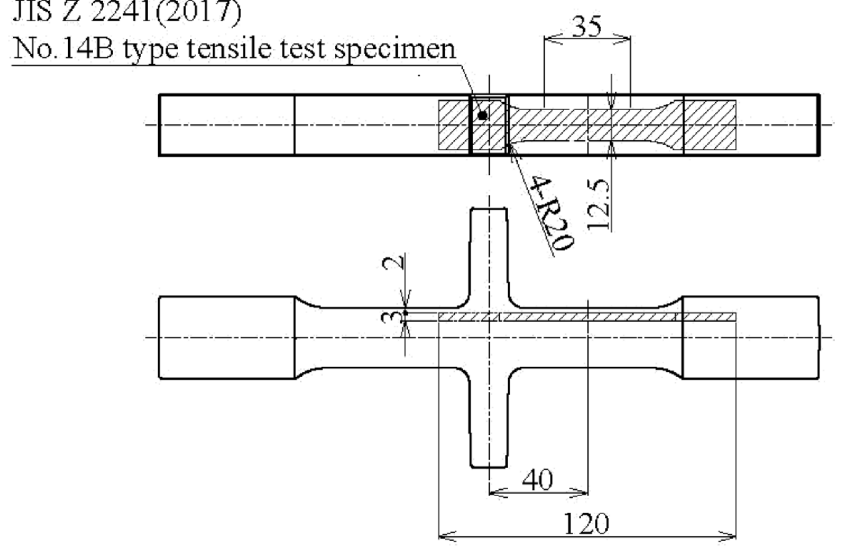

Fig. 5. Dimension and machining location of tensile test specimen.

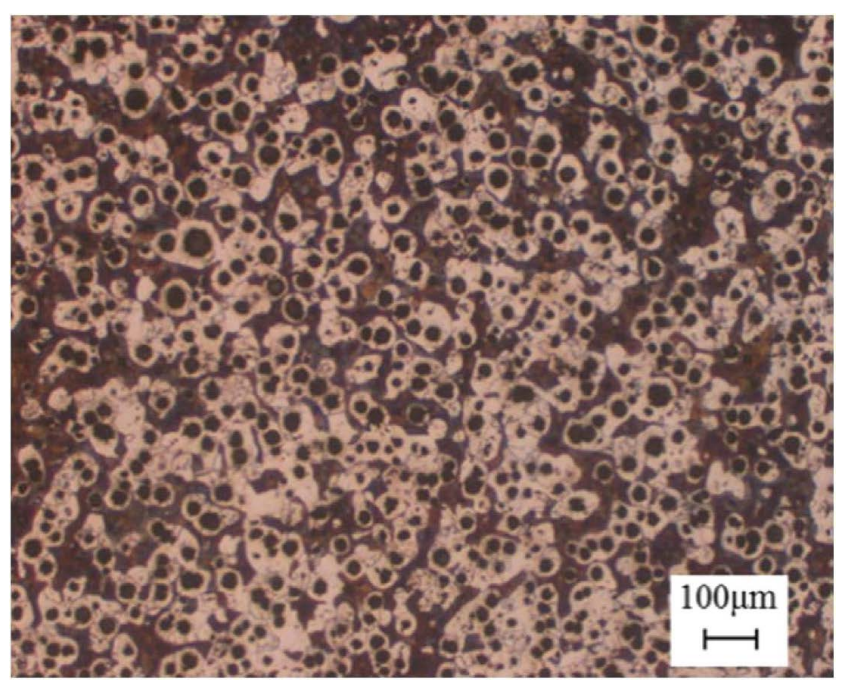

Fig. 6. Microstructure of DCI joint (Etched by nital). (Online version in color.) 
longitudinal direction of the test specimen according to the experimental condition of the welded joint. The fatigue test was carried out under load control at stress ratio $\mathrm{R}=0$. Where, $\mathrm{R}$ is defined as the minimum stress/maximum stress. An electro-hydraulic servo fatigue tester (manufactured by MTS) having a load capacity of $\pm 100 \mathrm{kN}$ was used as a fatigue testing machine. The repetitive waveform was a sine wave, and the frequency was $30 \mathrm{~Hz}$. Fatigue test was carried out in the atmosphere at room temperature $\left(23 \pm 3^{\circ} \mathrm{C}\right)$. The maximum stress decreases gradually from $350 \mathrm{MPa}$ by considering the specimen under $0.2 \%$ proof stress. Then, the fatigue experiment was performed up to the maximum number of cycle $N_{f}=10^{7}$.

\section{Fatigue Experimental Results}

\subsection{Fatigue Experimental Results of DCI Joint}

Figure 7 shows the $S-N$ diagram of DCI joint compared to DCI plate. Figure 7 also shows the $S-N$ diagram of the welded joint compared to the steel plate before welded in Fig. 2, which will be discussed in the next section. Table 5 shows the fracture position of DCI joint and the fracture origin confirmed on the fracture surface. The test specimen No. in the Table 5 corresponds to the number indicated in Fig. 7. In Fig. 7 and Table 5, since No. 7 specimen was not broken, No. $7^{*}$ is another test result of No. 7 where the maximum load stress was increased to $300 \mathrm{MPa}$ and the fatigue test was carried out again to confirm the fracture surface of No. 7. Here, this new test data of No. $7^{*}$ shown in Fig. 7 is not far away from the S-N diagram of DCI joint. This is because the increased maximum stress is sufficiently large and the coaxing effect does not appear. Therefore, it can be judged that No. $7^{*}$ data is valid and shown in Fig. 7.

As shown in Fig. 7, the fatigue strength of DCI joint $\sigma_{w 1}^{D C I}=220 \mathrm{MPa}$, which was about $90 \%$ of the fatigue strength of DCI plate $\sigma_{w 0}^{D C I}=240 \mathrm{MPa}$.

As shown in Table 5, except the specimen No. 5, the fracture position was fillet portion of the rib cross-section or the gripping portion where stress concentration exists. Also, relatively small inclusion defects were confirmed near the casting surface of the fracture surface. These defects are found to be the fracture origin from the aspect of the fracture surface. These defects are judged to be defects called sand inclusions or dross inclusions by mapping analysis. The defect size was about 1 to $2 \mathrm{~mm}$ in diameter when the defect shape is converted into a sphere.

Specimens No. 5 was fractured originating from the large defect like the internal cavity. This is probably the internal shrinkage cavity that often appears due to solidification shrinkage during casting. The fracture position of this specimen was a smooth portion slightly away from the stress concentration portion.

Regarding such relatively large defects, the casting plan should be modified during the trial production period and drastic measures should be taken to fit the defect size within acceptable regions. Moreover, sampling inspection by ultrasonic testing etc. should be carried out according to the number of lots. Regarding structurally important parts, quality control should be carried out so that the defect size becomes $\varphi 2 \mathrm{~mm}$ or less. In this study, radiographic testing was carried out for all of the test specimens, and the fatigue test was carried out after recognizing the presence of defects. Then, no internal shrinkage cavity was detected except for specimen No. 5.

Instead, although the details of the fractured origin of DCI plate with $t_{1}=12 \mathrm{~mm}$ are not described in this paper, all fracture positions are in the smooth portion, and the defect sizes were almost the same of the DCI joint with $t_{1}=24$ $\mathrm{mm}$. We will continue to discuss The detail will be discussed in the future study.

\subsection{Fatigue Strength Comparison of DCI Joint and Welded Joint}

The fatigue strength of the welded joint $\sigma_{w 1}^{\text {STEEL }}=80$ $\mathrm{MPa}$, while the fatigue strength of DCI joint $\sigma_{w 1}^{D C I}=220$ $\mathrm{MPa}$. It was confirmed that the fatigue strength of DCI joint is 2.75 times larger than the one of the welded joint. Also, from $\sigma_{w 1}^{\text {STEEL }} / \sigma_{w 0}^{\text {STEEL }}=30 \%$ and $\sigma_{w 1}^{D C I} / \sigma_{w 0}^{D C I}=90 \%$, it should be noted that the reduction rate of DCI joint is remarkably small.

As shown in Fig. 7, the slope of the $S-N$ diagram of DCI joint is smaller than that of the welded joint. This is because

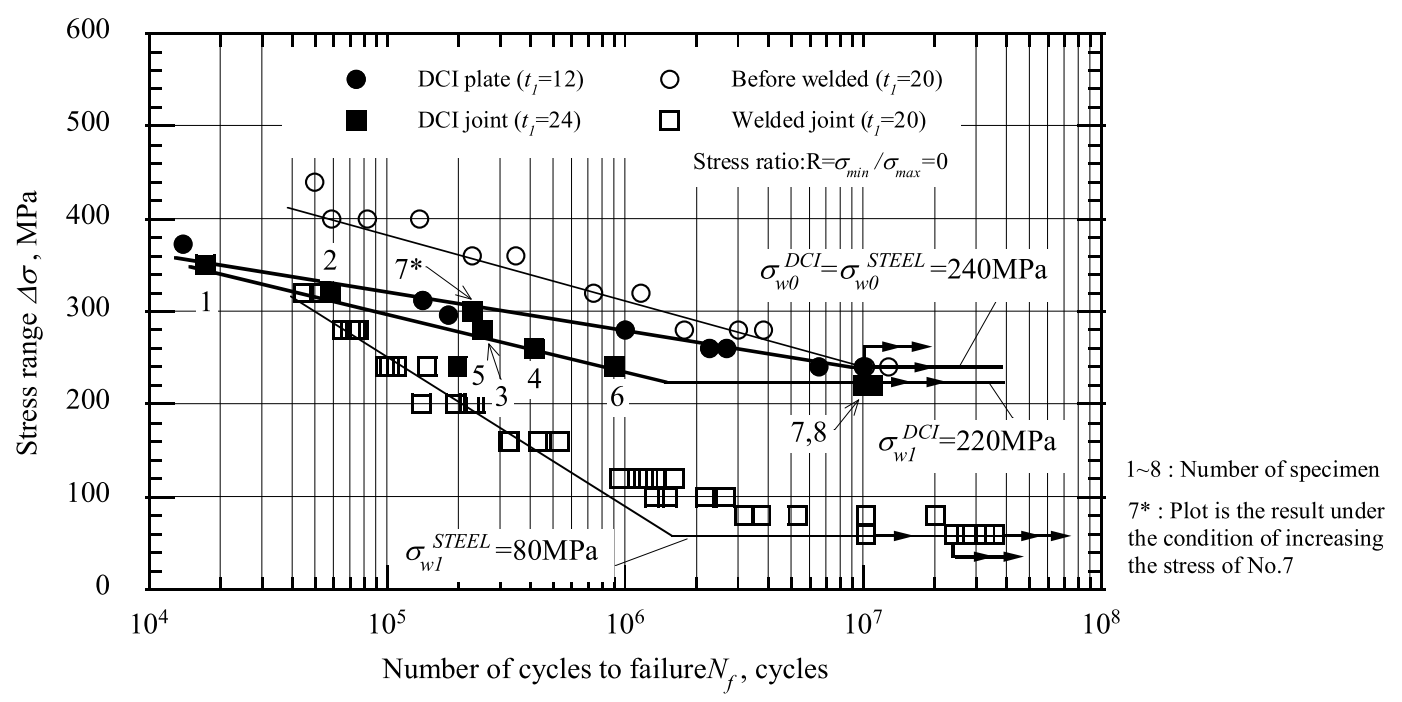

Fig. 7. $S-N$ diagram showing fatigue properties of DCI specimen and steel specimen. 
Table 5. Broken position and fracture origin of DCI joint in Fig. 7. (Online version in color.)

Number of specimen

Maximum load stress $\sigma_{\max }$

Number of cycles to falure $N_{f}$

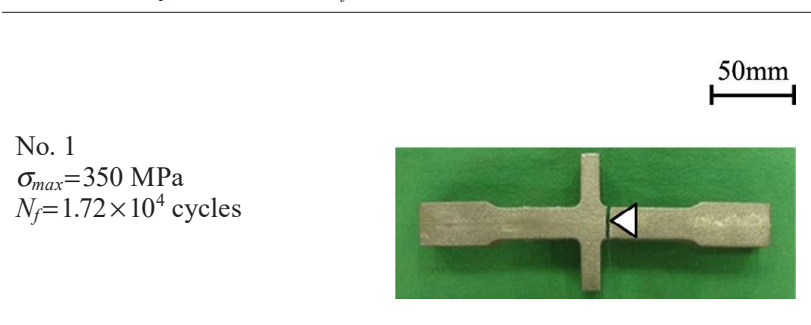

No. 2

$\sigma_{\max }=320 \mathrm{MPa}$

$N_{f}=5.77 \times 10^{4}$ cycles

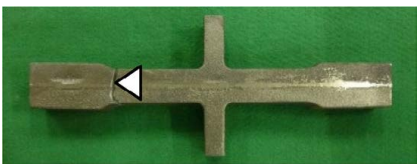

No. 3

$\sigma_{\max }=280 \mathrm{MPa}$

$N_{f}=2.52 \times 10^{5}$ cycles

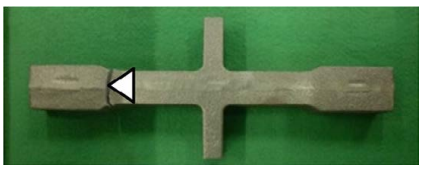

No. 4

$\sigma_{\max }=260 \mathrm{MPa}$

$N_{f}=4.14 \times 10^{5}$ cycles

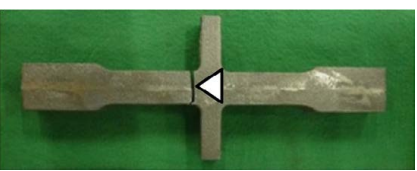

No. 5

$\sigma_{\max }=240 \mathrm{MPa}$

$N_{f}=1.99 \times 10^{5}$ cycles
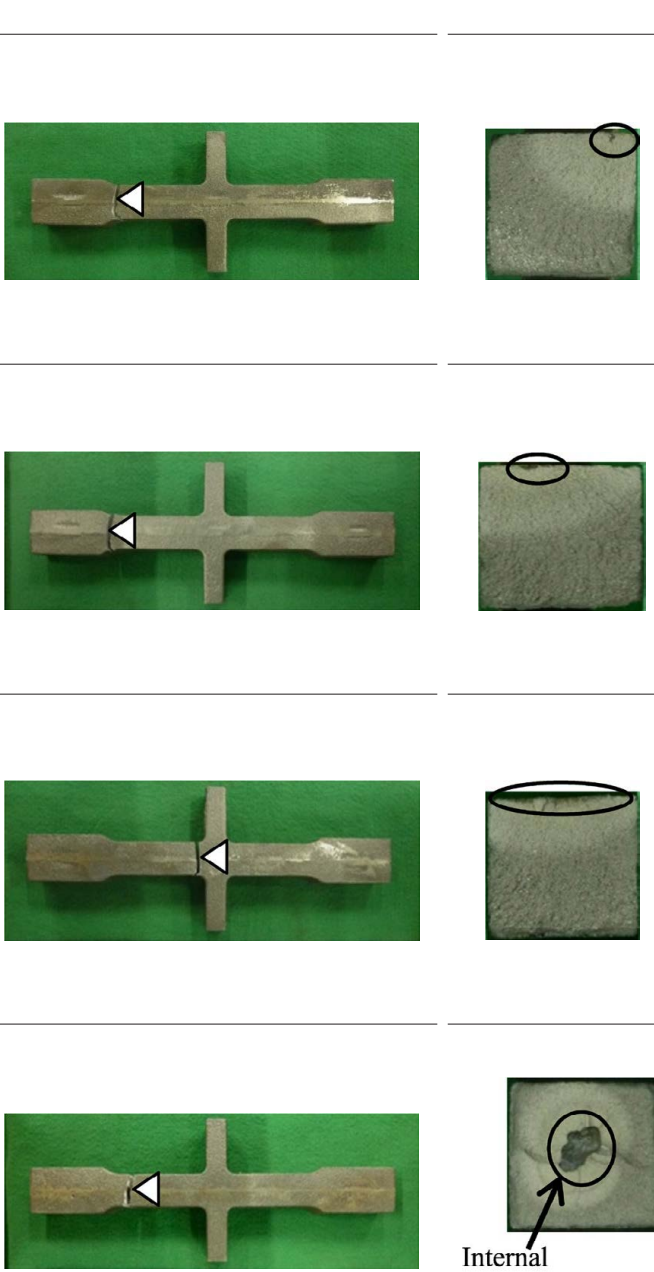

Fracture origin

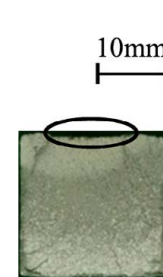

S3400 20.0kV ×30 S
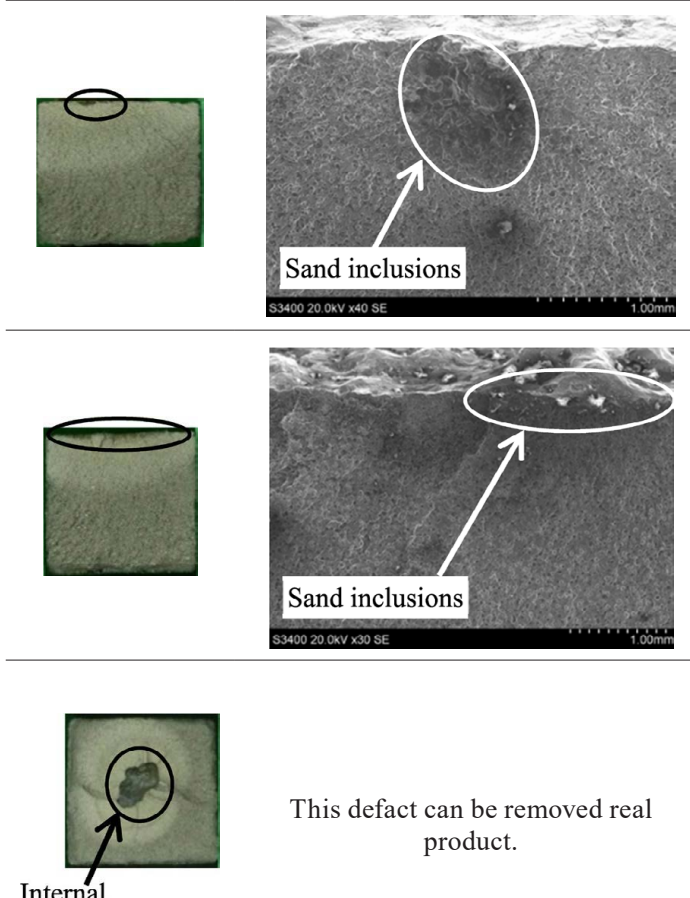

This defact can be removed real product.

No. 6

$\sigma_{\max }=240 \mathrm{MPa}$

$N_{f}=9.05 \times 10^{5}$ cycles
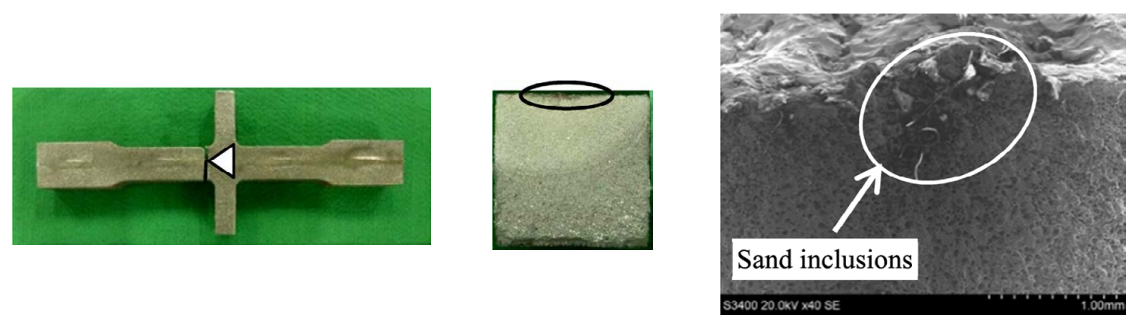

No. 7

$\sigma_{\max }=220 \mathrm{MPa}$

$N_{f} \geqq 1.00 \times 10^{7}$ cycles

No.7*

$\sigma_{\max }=300 \mathrm{MPa}$

$N_{f}=2.28 \times 10^{5}$ cycles
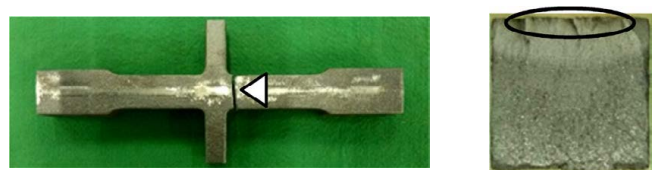
the notch effect of DCI joint is smaller than that of the welded joint. Generally, the fatigue strength is affected by stress concentration, notch insensitivity, and residual stress. Details will be discussed in the next section.

\section{Discussion Why the Fatigue Strength of DCI Joint is Superior to the One of Welded Joint?}

In this section, several factors will be discussed to clarify the reason why the fatigue strength of DCI joint is superior to the one of the welded joint.

\subsection{Fatigue Strength of Smooth Specimen}

Before comparing the fatigue strength of the welded joint and DCI joint, the fatigue strength of the smooth specimen should be identified by clarifying the surface state in the first place. They can be explained in the following way.

Table 6 shows the fatigue limit and surface condition of the smooth specimens of steel plate before welded and DCI plate. They have the same fatigue strength $240 \mathrm{MPa}$. On the steel plate surface, mill scale is formed. And on the DCI plate surface, shot blasting treatment is performed. The surface condition of the welded joint and DCI joint is the same as the one of the each smooth specimen.

\subsection{Difference of Stress Concentration Factor}

In order to compare the stress concentration, FEM analysis is performed for the welded joint geometry with $t_{1}=$ $20 \mathrm{~mm}$ and also for DCI joint geometry with $t_{1}=24 \mathrm{~mm}$. Then, the stress concentration factors at the fillet of the rib are investigated. In this analysis, FEM software MSC Marc 2012 has been used.

As shown in Fig. 8, a quarter region is considered for the analysis due to the symmetry. To analyze the welded joint, the flank angle is set to $45^{\circ}$ and the radius toe $\rho=0.485 \mathrm{~mm}$ is considered as an average value measured from actually welded joints. ${ }^{17)}$ To analyze DCI joint, the dimensions in Fig. 4 are considered. As shown in Fig. 8, $\sigma_{n}=1 \mathrm{MPa}$ is applied at the cross section to calculate the stress concentration as the boundary conditions.

Figure 9 shows the maximum stresses and principle stress distributions of the welded joint and DCI joint. The stress concentration factor $K_{t}$ shown in the figure is defined as $K_{t}=\sigma_{\max } / \sigma_{n}$. Here, $\sigma_{\max }$ is the maximum stress concentration at the fillet portion and $\sigma_{n}$ is the nominal stress at the minimum cross section. ${ }^{25-30)}$ It should be noted that in the definition of stress concentrating factor for the fillet the position where $\sigma_{\max }$ occurs differs from the position where $\sigma_{n}$ is defined as shown in Fig. 10. This definition has been used widely since $\sigma_{n}$ can be obtained at the minimum section and the maximum stress can be obtained conveniently

Table 6. Fatigue limit and surface condition of steel plate before welded and DCI plate.

\begin{tabular}{ccc}
\hline Specimen type & $\begin{array}{c}\text { Fatigue limit } \\
\Delta \sigma(\mathrm{MPa})\end{array}$ & Surface condition \\
\hline $\begin{array}{c}\text { Steel plate } \\
\text { before welded }\end{array}$ & 240 & Mill scale \\
DCI plate & 240 & $\begin{array}{c}\text { Casting surface with } \\
\text { shot blast }\end{array}$ \\
\hline
\end{tabular}

for strength design.

From Fig. 9, it is found that $K_{t}=1.68$ for DCI joint is smaller than the welded joint $K_{t}=3.47$. This is because $\rho$ of DCI joint is larger than that of the welded joint. Since DCI

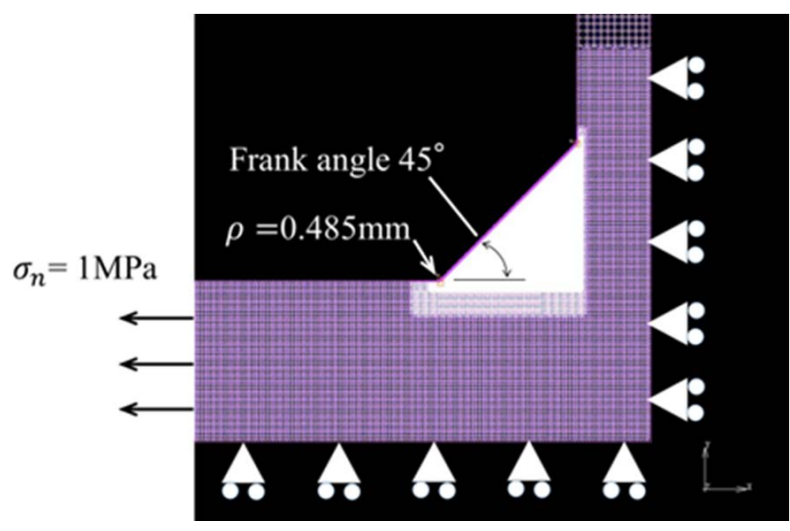

(a) FEM model welded joint $\left(t_{1}=20\right)$

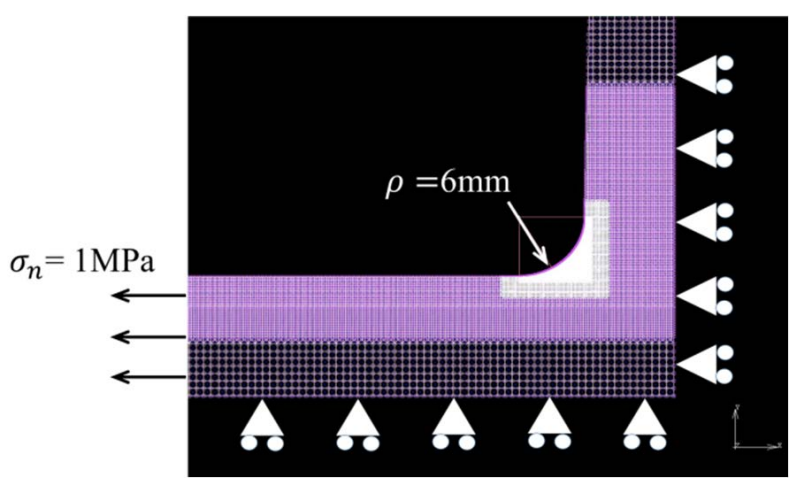

(b) FEM model DCI joint $\left(t_{1}=24\right)$

Fig. 8. FEM model and boundary conditions. (Online version in color.)

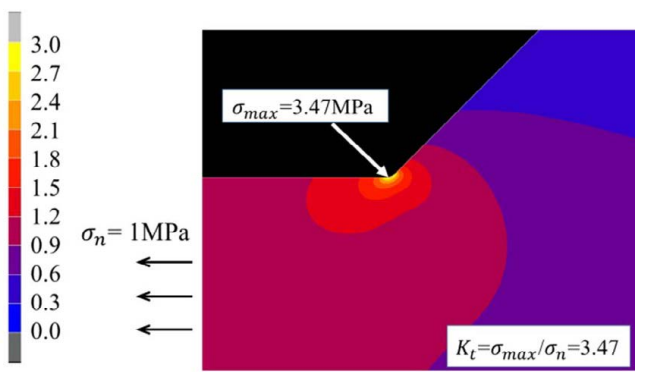

(a) The maximum principal stress distribution of welded joint $\left(t_{1}=20\right)$

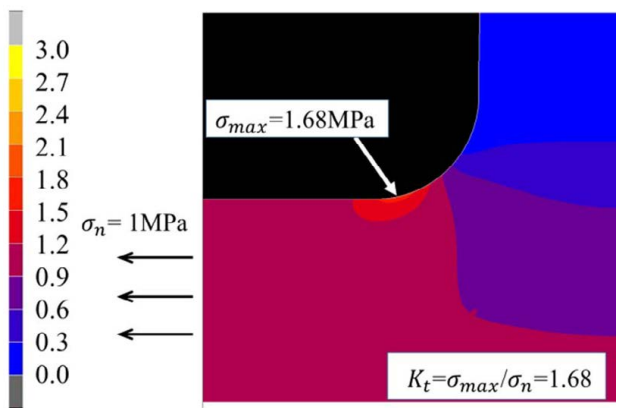

(b) The maximum principal stress distribution of DCI joint $\left(t_{1}=24\right)$

Fig. 9. Results of stress simulation by 2D FEM. (Online version in color.) 


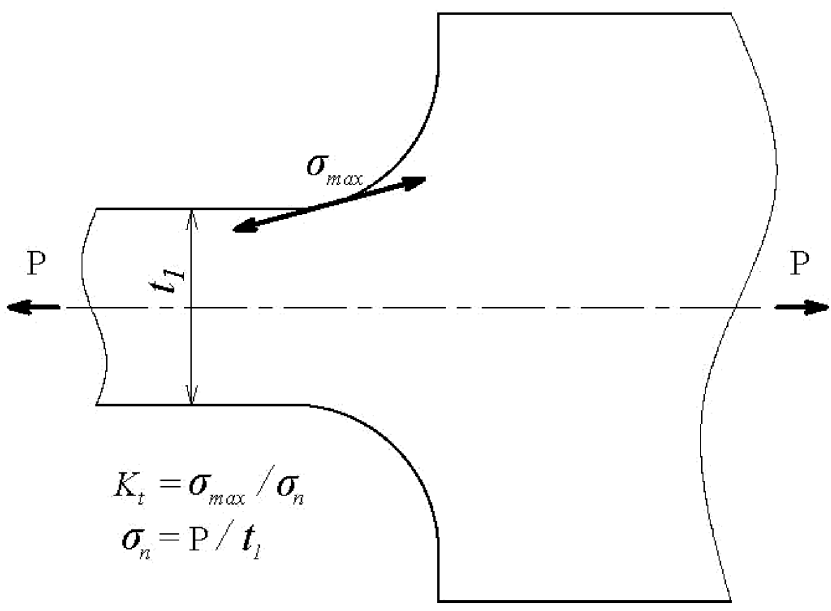

Fig. 10. Stress concentration factor of a stepped flat bar with shoulder fillets.

joint has smaller stress concentration, the fatigue strength can be improved by replacing the welded joint with DCI joint. Since DCI joint may have larger root radius $\rho$, the strength can be improved more through casting design.

\subsection{Difference of Notch Sensitivity}

The fatigue experiment in Fig. 7 shows that $\sigma_{w 0}^{D C I}=240$ $\mathrm{MPa}$ and $\sigma_{w 1}^{D C I}=220 \mathrm{MPa}$ have very small difference. In other words, the ductile cast iron is hardly affected by the stress concentration because of the notch-insensitivity. Figure 11 shows the relationship between the stress gradient $\chi$ and the maximum stress $\sigma_{\max } / \sigma_{w 0}=K_{t} \sigma_{w 1} / \sigma_{w 0}$ at a notch root. This figure shows the notch insensitivity of ferrous materials by varying the notch root radius $\rho .^{31,32)}$ Since there is no experimental data for FCD550 of DCI whose tensile strength $\sigma_{B}=550 \mathrm{MPa}$, the curve of FCD550 in Fig. 11 is estimated from the curve of FCD700 whose $\sigma_{B}=730$ $\mathrm{MPa}$ by considering the results of $\operatorname{S10C}\left(\sigma_{B}=372 \mathrm{MPa}\right)$ and $\operatorname{S30C}\left(\sigma_{B}=537 \mathrm{MPa}\right)$ and $\sigma_{\max } / \sigma_{w 0}$. It is seen that FCD550 and FCD700 have larger maximum stress $\sigma_{\max } / \sigma w_{0}$ compared to S10C and S30C under the same stress gradient $\chi$. Therefore, the ductile cast irons are very notch-insensitive compared to mild steel.

In Fig. 11, $\sigma_{\max } / \sigma_{w 0}=K_{t} \sigma_{w 1} / \sigma_{w 0}$ is the relative maximum stress repeated under the fatigue limit of notched specimen based on the crack initiation $\sigma_{w 1}, K_{t}$ is the stress concentration factor, and $\sigma_{w 0}$ is the fatigue limit of the smooth specimen. The broken line $K_{t} \sigma_{w 1} / \sigma_{w 0}=1$ means the fatigue limit $\sigma_{w 1}$ is independent of $\chi$. Since fatigue notch factor can be defined as $K_{f}=\sigma_{w 0} / \sigma_{w 1}, K_{t} \sigma_{w 1} / \sigma w_{0}=1$ is equivalent to $K_{t}=$ $K_{f}$. Therefore, the broken line $K_{t} \sigma_{w 1} / \sigma_{w 0}=1$ means extreme notch-sensitive case where $\sigma_{w 1}$ is controlled by $\sigma_{\max }=K_{t} \sigma_{w 1}$ alone. Such extreme notch-sensitivity can be seen for spring steel. ${ }^{33)}$ Conversely, if $\sigma_{\max } / \sigma_{w 0}=K_{t} / K_{f}$ increases largely with increasing stress gradient $\chi$ and decreasing notch root radius $\rho$, it can be said that the material is notch-insensitive. As shown in Fig. 11, it is known that the notch insensitivity of ferrous materials is strongly correlated with the tensile strength unless the chemical composition and the matrix structure are significantly different. ${ }^{33)}$

Based on the above, the fatigue limit of the welded joint and DCI joint will be estimated. For the welded joint, we

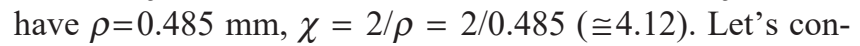

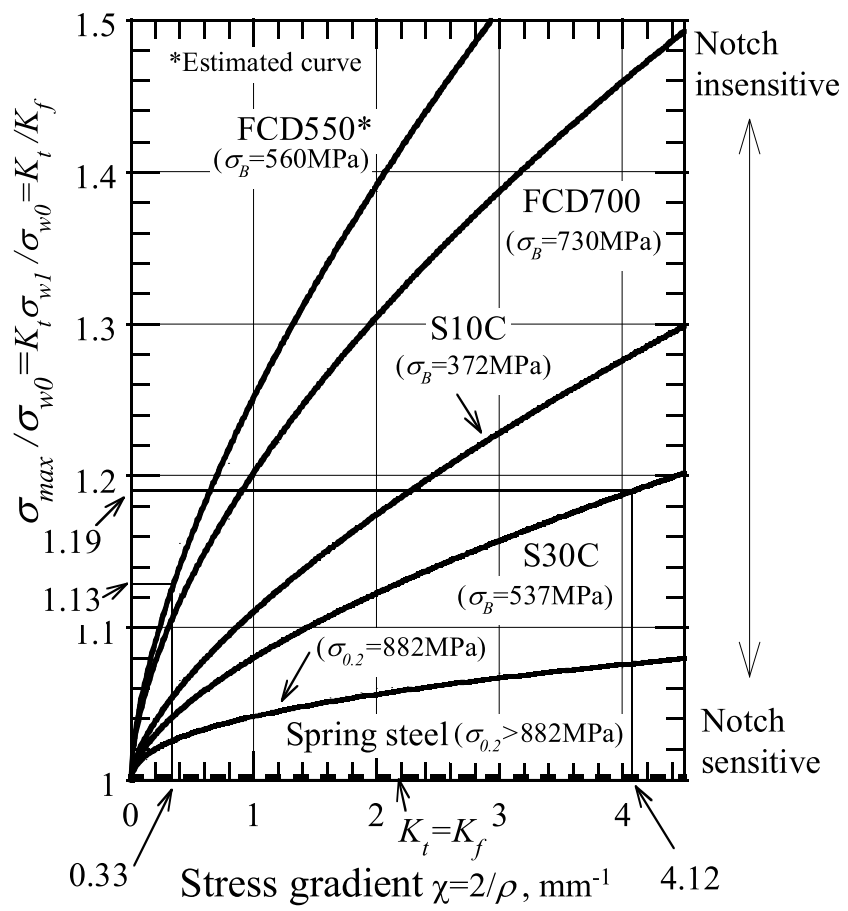

Fig. 11. Notch insensitivity (Relationship between the stress gradient and the maximum elastic stress at a notch root).

sider S30C whose strength is close to the one of the base material SM50B. Figure 11 shows $K_{t} \sigma_{w 1} / \sigma_{w 0} \cong 1.19$ when $\chi=2 / \rho \cong 4.12$. According to the analysis result in the previous section, since $K_{t}=3.47, \sigma_{w 1} / \sigma_{w 0} \cong 0.34$ is obtained. That is, the fatigue limit of this welded joint is $34 \%$ of the fatigue limit of the smooth specimen. Therefore, since the fatigue limit of the steel plate before welded is $240 \mathrm{MPa}$, the welded joint strength can be estimated to be $82 \mathrm{MPa}$.

On the other hand, for DCI joint, we have $\chi=2 / \rho=2 / 6$ $(\cong 0.33)$. Therefore, FCD550 in Fig. 11 shows $K_{t} \sigma_{w 1} / \sigma_{w 0} \cong$ 1.13. Since $K_{t}=1.68, \sigma_{w 1} / \sigma_{w 0} \cong 0.67$. Since $\sigma_{w 0}^{D C I}=240$ $\mathrm{MPa}, \sigma_{w 1}^{D C I}=161 \mathrm{MPa}$ can be obtained. This estimated value is about twice as large as the welded joint. The fatigue limit of DCI joint can be greatly improved over the welded joint.

\subsection{Difference in Residual Stress}

Table 7 shows the average residual stress of the DCI joint measured experimentally in comparison with the welded joint. Measurement points are also shown in Table 7 at the fillets where the maximum stress appears under loading. The value of the welded joint in Table 7 is the result in the reference 34). This value is the average value of four points A to D in Table 7. The value of DCI joint in Table 7 is the average value obtained from three specimens manufactured from the same lot used for the fatigue experiment. An X-ray residual stress measuring device was used for the measurement. Table 8 shows the measuring conditions. The residual stresses are measured for both welded and DCI joints before fatigue experiment.

Table 7 shows the residual stress of the welded joint is $100 \mathrm{MPa}$, which is smaller than the values about $200 \mathrm{MPa}$ to $300 \mathrm{MPa}$ reported previously. It should be noted that in this study the residual stresses were measured at the points about $3 \mathrm{~mm}$ away from the weld toe and larger residual stresses may exist at the welding toe. On the other hand, Table 7 shows compressive residual stress larger than $300 \mathrm{MPa}$ 
Table 7. Residual stress and measuring point of welded joint and DCI joint.

\begin{tabular}{lclll}
\hline Specimen type & $\begin{array}{c}\text { Residual stress } \\
\sigma_{\text {res }}(\mathrm{MPa})\end{array}$ & Measuring point \\
Welded joint & 100 & \\
DCI joint & -305 &
\end{tabular}

Table 8. Residual stress measurement condition of DCI joint.

\begin{tabular}{cc}
\hline X-ray & $\mathrm{CrK} \alpha$ \\
\hline Diffraction plane & $\mathrm{Fe}(211)$ \\
Filter & $\mathrm{V}$ \\
Stress constant $(\mathrm{MPa} / \mathrm{deg})$. & -323 \\
Tube voltage $(\mathrm{kV})$ & 30 \\
Tube current $(\mathrm{mA})$ & 10 \\
Collimator $(\mathrm{mm})$ & 2 \\
Incident angle $\varphi 0(\mathrm{deg})$. & 0 \\
Measuring method & Half height breadth \\
\hline
\end{tabular}

appears in DCI joint. This is due to the shot blasting treatment and the result is close to the residual stress obtained by the same treatment. ${ }^{35,36)}$

Let's consider those residual stress effects on the fatigue strength. Residual stress may decrease under repeated stress. ${ }^{22,36)}$ For the welded joint, the initial residual stress may affect the fatigue strength when residual stress is not large. ${ }^{11)}$ Since the residual stress for the welded joint in Table 7 is relatively small, the residual stress $100 \mathrm{MPa}$ is assumed to affect the fatigue strength without decreasing.

On the other hand, for DCI joint, the residual stress due to shot blasting takes the maximum value at the surface layer and decreases with increasing the depth. Then, it was reported that the residual stress almost disappears around the depth of $500 \mu \mathrm{m}$ to $1000 \mu \mathrm{m}$ from the surface layer. ${ }^{36)}$ It can be estimated that the defect size in the vicinity of the surface layer is about $1000 \mu \mathrm{m}$ when the defect can be the fracture origin. Since this $1000 \mu \mathrm{m}$ defect is subjected to $-305 \mathrm{MPa}$ at the surface and $0 \mathrm{MPa}$ at the deepest point, it can be assumed this defect is subjected to about the half of $-305 \mathrm{MPa}$, that is, $-150 \mathrm{MPa}$. Therefore, the residual stress $-150 \mathrm{MPa}$ is assumed to affect the fatigue strength of DCI joint.

Figure 12 shows the fatigue limit diagram of the welded and DCI joints. Here, the fatigue limit under reversed loading $\sigma_{w}$ is estimated from tensile strength $\sigma_{B}$ as $\sigma_{w}=0.48 \sigma_{B}$ as shown in Eq. (1). ${ }^{37)}$ The fatigue limit under pulsating tension $\sigma_{1}$ in Fig. 12 can be expressed as shown in Eq. (2) : $\sigma_{1}=$ $\sigma_{w} /\left(1+\sigma_{w} / \sigma_{B}\right)$. The fatigue limit $\sigma_{2}$ when the residual stress

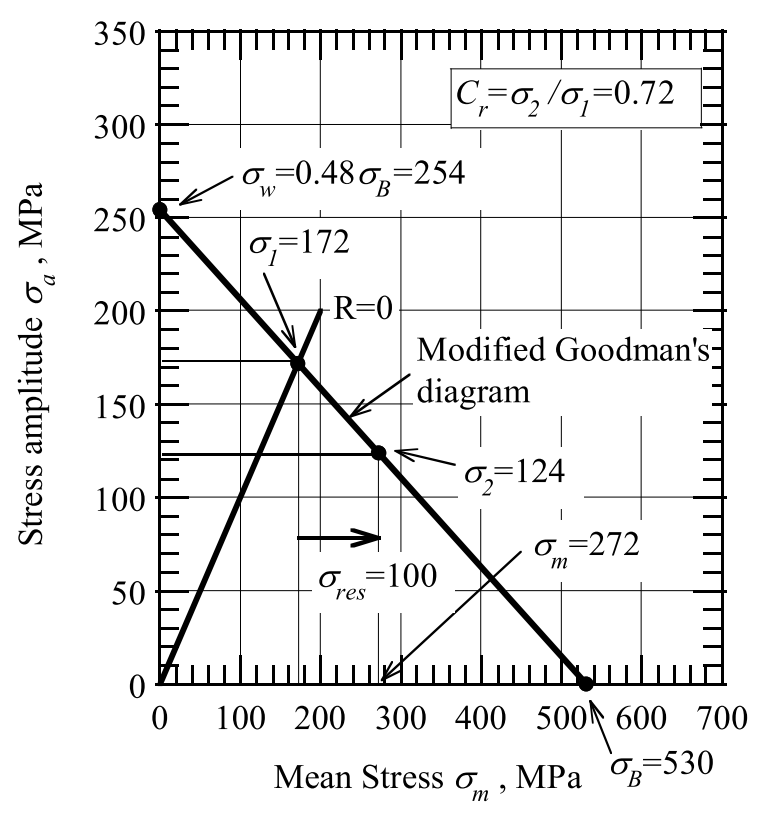

(a) Welded joint

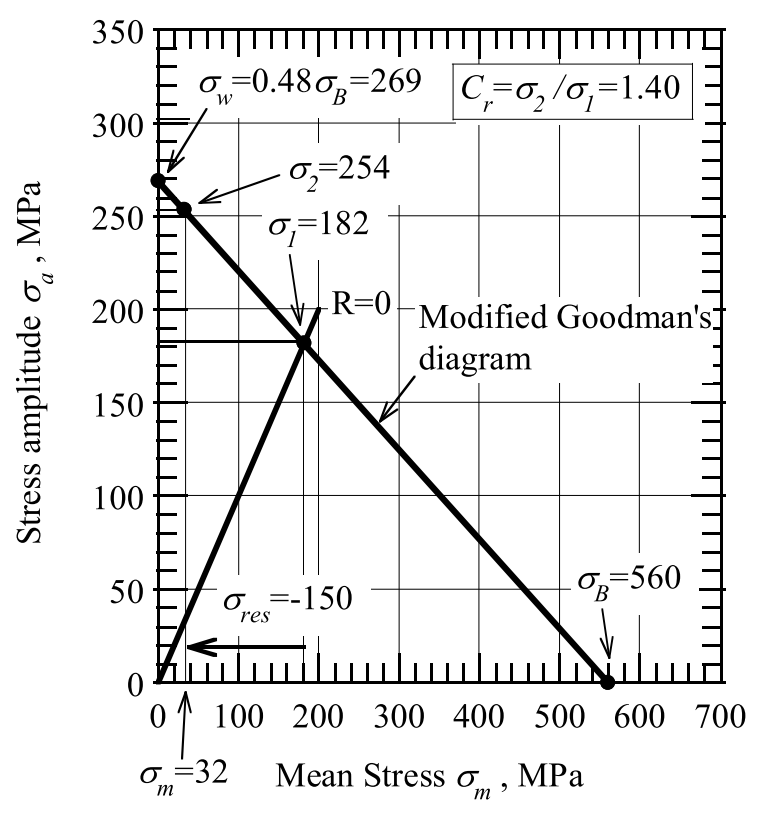

(b) DCI joint

Fig. 12. Fatigue limit diagram showing the effect of residual stress.

$\sigma_{\text {res }}$ acts as the mean stress can be expressed in Eq. (3) $: \sigma_{2}=$ $\sigma_{w}\left\{1-\left(\sigma_{1}+\sigma_{r e s}\right) / \sigma_{B}\right\}$. The effect of the residual stress can be expressed as the fatigue strength ratio $C_{r}=\sigma_{2} / \sigma_{1}$ in Eq. (4).

As shown in Fig. 12, for the welded joint, the fatigue strength ratio $C_{r}=0.72$. On the other hand, for the DCI joint, $C_{r}=1.4$. In other word, the fatigue strength of DCI joint is improved significantly by the residual stress compared to the fatigue strength of the welded joint.

$$
\begin{array}{r}
\sigma_{w}=0.48 \sigma_{B} \ldots \ldots \ldots \ldots \\
\sigma_{1}=\sigma_{w} /\left(1+\sigma_{w} / \sigma_{B}\right) \ldots \ldots \\
\sigma_{2}=\sigma_{w}\left\{1-\left(\sigma_{1}+\sigma_{\text {res }}\right) / \sigma_{B}\right\}
\end{array}
$$




$$
C_{r}=\sigma_{2} / \sigma_{1}
$$

$\sigma_{w}$ : Completely reversed fatigue limit (MPa)

$\sigma_{B}$ : Tensile strength (MPa)

$\sigma_{\text {res: }}:$ Residual stress (MPa)

$\sigma_{1}:$ Fatigue limit without residual stress (MPa)

$\sigma_{2}:$ Fatigue limit with residual stress (MPa)

$C_{r}$ : Fatigue strength change rate due to residual stress

\subsection{The Effect of Various Factors on Fatigue Limit}

Figure 13 schematically illustrates several effects on the fatigue strength as a summary of this section. The welded joint strength and DCI joint strength are discussed on the basis of the fatigue strengths of the smooth specimens. The following three factors are considered. (1) Stress concentration factor denoted by $K_{t}$ effect, (2) Notch insensitivity

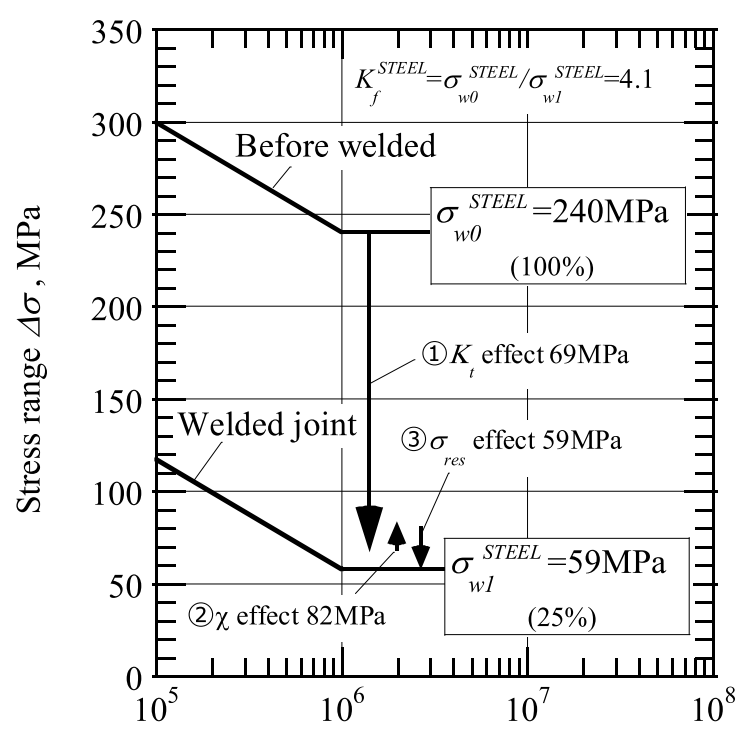

Number of cycles to failure $N_{f}$, cycles

(a) Welded joint

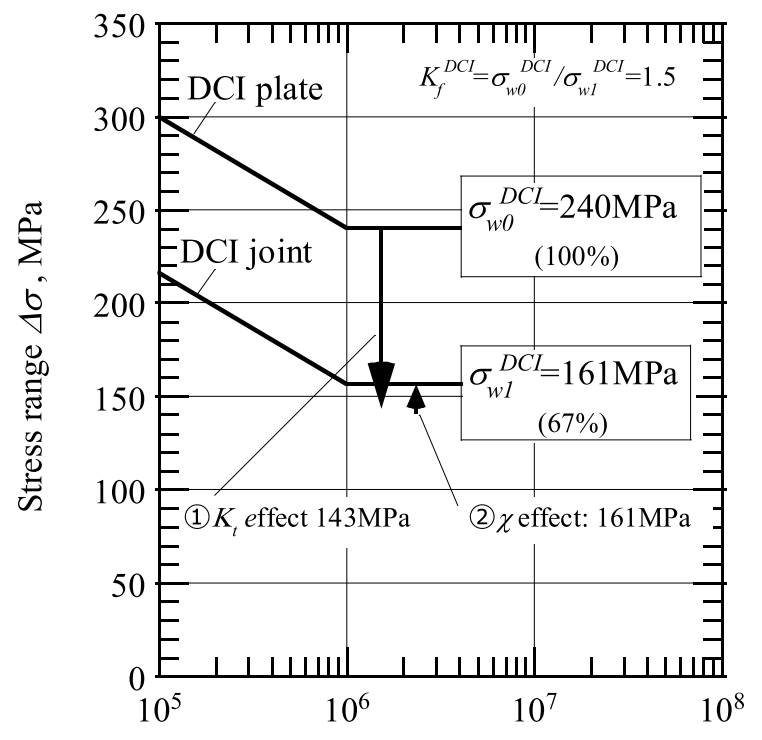

Number of cycles to failure $N_{f}$, cycles

(b) DCI joint

Fig. 13. Effects of various factors on fatigue limit. denoted by $\chi$ effect and (3) Residual stress denoted by $\sigma_{\text {res }}$ effect, all of which were discussed in this section. Regarding the welded joints, (1) $K_{t}$ effect reduces the fatigue strength significantly as $240 \mathrm{MPa} \rightarrow 69 \mathrm{MPa}$. Although the fatigue limit is somewhat improved by (2) $\chi$ effect as $69 \mathrm{MPa} \rightarrow 82$ $\mathrm{MPa}$, this effect is comparatively smaller. Thirdly, (3) $\sigma_{\text {res }}$ effect may reduce the fatigue strength more as $82 \mathrm{MPa} \rightarrow$ $59 \mathrm{MPa}$. Totally, the fatigue strength of the welded joint can be estimated as $59 \mathrm{MPa}$, which is about $25 \%$ of the fatigue strength of the steel plate before welded $\left(\sigma_{w 0}^{\text {STEEL }}=240 \mathrm{MPa}\right)$.

On the other hand, regarding DCI joint, (1) $K_{t}$ effect reduces the fatigue strength, but the effect is small as 240 $\mathrm{MPa} \rightarrow 143 \mathrm{MPa}$. Secondly, due to (2) $\chi$ effect, the strength can be estimated as $143 \mathrm{MPa} \rightarrow 161 \mathrm{MPa}$. As a result, the fatigue strength of DCI joint is approximately $67 \%$ of the one of DCI plate. It should be noted that (3) $\sigma_{\text {res }}$ effect is not indicated in Fig. 13(b) because both DCI joint and DCI plate are similarly affected by (3) $\sigma_{\text {res }}$ effect and therefore the effect should be deleted in Fig. 13(b).

From the above discussion, the fatigue strength of DCI joint can be estimated to be 2.7 times or more larger than that of the welded joint. Therefore, it may be concluded that DCI joint has better fatigue strength. The fatigue notch factor of DCI joint $K_{f}^{D C I}=\sigma_{w 0}^{D C I} / \sigma_{W 1}^{D C I}$ is about $1 / 3$ of that of the welded joint $K_{f}^{\text {STEEL }}=\sigma_{w 0}^{\text {STEEL }} / \sigma_{w 1}^{\text {STEEL }}$, DCI joint is notch-insensitive compared to the welded joint. These estimated results in Fig. 13 agree with the experimental values shown in Fig. 7 within 25\% error.

\section{Conclusion}

In this study, the fatigue strength of DCI joints was compared with the fatigue strength of welded joint under the same main plate thickness. The conclusions can be summarized as follows:

(1) The present experimental results show that the fatigue strength of DCI joint $\sigma_{w 1}^{D C I}=220 \mathrm{MPa}$ is about 2.7 times larger than the fatigue strength of welded joint $\sigma_{w 1}^{\text {STEEL }}=80 \mathrm{MPa}$. The strength of welded structures can be improved by using DCI joints.

(2) In this study the fatigue strength was also estimated theoretically from the stress concentration and the notch sensitivity. The estimated results from the smooth specimen show that the DCI joint strength $\sigma_{w 1}^{D C I}=161 \mathrm{MPa}$ is also 2.7 times larger than the estimated value of welded joint $\sigma_{w 1}^{\text {STEEL }}=59 \mathrm{MPa}$. The fatigue strength improvement was confirmed theoretically.

(3) Compared with welded joints, DCI joints have smaller stress concentration factors, smaller notch sensitivities and compressive surface residual stresses due to shot blasting. This is the reason why the DCI fatigue strength is larger than the welded joint fatigue strength.

\section{Future Work}

DCI joints were fractured originating from the defects. Also, the casting surface roughness for DCI joints is fairly large. However, in this research, the effects of these on fatigue strength have not been considered.

From the above, in the next research, the lowest fatigue strength for DCI joints will be estimated considering the 
effects of the maximum defect size and casting surface roughness, and compared with the fatigue strength for the welded joints.

\section{Acknowledgments}

This research was conducted by FY 2017 subsidies for basic research (Saga prefecture technology promotion support technology industry, academia and government collaboration technological innovation support project). We express our deep appreciation.

\section{REFERENCES}

1) C. Miki, H. Suganuma, M. Tomizawa and F. Machida: Proc. Jpn. Soc. Civ. Eng., 780 (2005), 57 (in Japanese).

2) S. Ono, Y. Hirabayashi, T. Shimozato, N. Inaba, M. Murano and C. Miki: Proc. Jpn. Soc. Civ. Eng. A, 65 (2009), 335 (in Japanese).

3) J. M. Borrajo, R. A. Martínez, R. E. Boeri and J. A. Sikora: ISIJ Int., 42 (2002), 257

4) R. Ivanova, W. Sha and S. Malinov: ISIJ Int., 44 (2004), 896.

5) B. Bosnjak, B. Radulovic, K. P. Tonev and V. Asanovic: ISIJ Int., 40 (2000), 1246

6) M. Takanezawa, Y. Tomota and Y. Kobayashi: ISIJ Int., 38 (1998), 106.

7) M. D. Echeverría, O. J. Moncada and J. A. Sikora: ISIJ Int., 41 (2001), 25

8) H. Tobinaga, M. Murayama, E. Saeki, T. Tamakoshi, E. Yamaguchi and C. Miki: Kou kouzou ronbunshuu, 24 (2017), No. 95, 13 (in Japanese).

9) M. Yano: J. JFS, 77 (2005), 641 (in Japanese).

10) I. Ovali, V. Kilicli and M. Erdogan: ISIJ Int., 53 (2013), 375.

11) H. Shirasawa: ISIJ Int., 34 (1994), 285.

12) P. J. J. Ratto, A. F. Ansaldi, V. E. Fierro, F. R. Agüera, H. N. A. Villar and J. A. Sikora: ISIJ Int., 41 (2001), 372.

13) A. Basso, M. Caldera, G. Rivera and J. Sikora: ISIJ Int., 52 (2012), 1130

14) Z. Liu, G. Zhou, Y. Qiu and G. Wang: ISIJ Int., 50 (2010), 531.

15) N. Tsunekage and H. Tsubakino: ISIJ Int., 41 (2001), 498.
16) Japanese Society of Steel Construction: Fatigue Design Recommendations for Steel Structures, Gihodo Shuppan, Tokyo, (2012), 33 (in Japanese).

17) NRIM Fatigue Data Sheet, No. 13, National Research Institute for Metals, Tokyo, (1979), 1.

18) M. Kamakura, M. Nihei, E. Sasaki, M. Kanao and M. Inagaki: J. Jpn. Weld. Soc., 48 (1979), 1060 (in Japanese).

19) M. Ohata: J. Jpn. Weld. Soc., 77 (2008), 678 (in Japanese).

20) C. M. Sonsino: Int. J. Fatigue, 31 (2009), 88.

21) E. Harati, L. Karlsson, L.-E. Svensson and K. Dalaei: Int. J. Fatigue, 77 (2015), 160.

22) K. Matsuoka, I. Takahashi, T. Yoshii and E. Fujii: Q. J. Jpn. Weld. Soc., 9 (1991), 36 (in Japanese).

23) T. Shiota, M. Hatate and K. Takemoto: J. JFS, 69 (1997), 904 (in Japanese).

24) S. Boonmee, M. K. Moran and D. M. Stefanescu: AFS Proc. 2011, American Foundry Society, Schaumburg, IL, (2011), 11.

25) M. Kaneda and Y. Yamamoto: Mechanical Design Engineering, Rikogakusha Publishing, Tokyo, (1995), 18 (in Japanese).

26) R. E. Peterson: Stress Concentration Factors, John Wiley \& Sons, New York, (1974), 96.

27) N. A. Noda, T. Saeki and H. Nishitani: Trans. Jpn. Soc. Mech. Eng. $A, 55$ (1989), 69 (in Japanese).

28) N. A. Noda, Y. Takase and K. Monda: Int. J. Fatigue, 19 (1997), 75.

$29)$ N. A. Noda and Y. Takase: Fatigue Fract. Eng. Mater. Struct., 26 (2003), 245.

30) N. A. Noda and Y. Takase: J. Test. Eval., 32 (2004), 217.

31) H. Nishitani, H. Noguchi, H. Uchihori and H. Nakae: Trans. Jpn. Soc. Mech. Eng. A, 54 (1988), 1293 (in Japanese).

32) H. Nishitani, S. Uchiyama, H. Nakae and H. Noguchi: Trans. Jpn. Soc. Mech. Eng. A, 58 (1992), 2280 (in Japanese).

33) Y. Murakami: Metal Fatigue Effects of Small Defects and Nonmetallic Inclusions, Yokendo Ltd., Tokyo, (2014), 27 (in Japanese).

34) NIMS Fatigue Data Sheet, No. 91, National Institute For Materials Science, Tokyo, (2003), 4.

35) S. Aoyama, M. Ito and S. Asano: J. Soc. Mater. Sci. Jpn., 27 (1978), 895 (in Japanese)

36) J. Yamabe, M. Kobayashi and N. Nakajima: Trans. Jpn. Soc. Mech. Eng. A, 71 (2005), 1690 (in Japanese).

37) K. Asami and Y. Kitsunai: J. Soc. Mater. Sci. Jpn., 35 (1986), 550 (in Japanese). 